\title{
Cytotoxic, anti-biofilm and antimicrobial polyketides from the plant associated fungus Chaetosphaeronema achilleae
}

\author{
Abolfazl Narmani ${ }^{\mathrm{a}, \mathrm{b}}$, Rémy Bertrand Teponno ${ }^{\mathrm{a}, \mathrm{c}}$, Soleiman E. Helaly ${ }^{\mathrm{a}, \mathrm{d}}$, Mahdi \\ Arzanlou ${ }^{\mathrm{b}}$, Marc Stadler ${ }^{\mathrm{a}, *}$ \\ a Department of Microbial Drugs, Helmholtz Centre for Infection Research and German \\ Centre for Infection Research (DZIF), partner site Hannover/Braunschweig, Inhoffenstrasse \\ 7, 38124 Braunschweig, Germany \\ ${ }^{b}$ Department of Plant Protection, Faculty of Agriculture, University of Tabriz, Tabriz, Iran \\ c Department of Chemistry, Faculty of Science, University of Dschang, P.O. Box 67, \\ Dschang, Cameroon \\ ${ }^{d}$ Department of Chemistry, Faculty of Science, Aswan University, 81528 Aswan, Egypt \\ * Correspondence: marc.stadler@helmholtz-hzi.de ; Tel.: +49 531 6181-4240; Fax: +49 \\ 53161819499
}

\begin{abstract}
From extracts of the plant associated fungus Chaetosphaeronema achilleae collected in Iran, a previously unreported isoindolinone named chaetosisoindolinone (1) and a previously undescribed indanone named chaetosindanone (2) were isolated in addition to five known metabolites, 2-(2-acetyl-3,5-dihydroxyphenyl) acetic acid (3), vulculic acid (4), 2-(2-acetyl-3hydroxy-5-methoxyphenyl)acetic acid (5), curvulin (6), and curvulol (7). Their structures were elucidated on the basis of extensive spectroscopic analysis and high-resolution mass spectrometry. The isolated compounds were tested for their antimicrobial, anti-biofilm, and nematicidal activities. Compound $\mathbf{2}$ exhibited cytotoxicity against the human breast adenocarcinoma MCF-7 cells with an $\mathrm{IC}_{50}$ value of $1.5 \mu \mathrm{g} / \mathrm{mL}$. Furthermore, compounds 4 and 7 almost completely inhibited biofilm formation in Staphylococcus aureus at $256 \mu \mathrm{g} / \mathrm{mL}$. Weak antimicrobial activities were also observed for some of the isolated compounds against Mucor hiemalis, Rhodoturula glutinis, Chromobacterium violaceum, and Staphylococcus aureus.
\end{abstract}

Keywords: Antibiotics; fungi; polyketides; Secondary metabolites 


\section{Introduction}

In the last decades, the emergence of multidrug resistance in many pathogens, drugresistant cancer cells and emergence of life-threatening viral diseases, is a problem of medical concern. Nowadays, the need for new and efficient pharmaceutical compounds for developing novel antimicrobial drugs, especially those from natural origin and without side effects is felt more than ever. In this regard, endophytic fungi in symptomless plants have been shown to be a promising source of antimicrobial compounds. Fungal endophytes represent a large reservoir of biological resources including bioactive compounds with potential applications in medicine, industry and agriculture, including pathogen control (Bills and Gloer, 2016). To explore the diversity of endophytic fungi inhabiting forest trees in Iran, a foray was conducted in September 2016, and symptomless, apparently healthy shoots were collected from English Yew (Taxus baccata) in northwestern Iran, and fungal endophytes were obtained by using a classical methodology based on surface sterilization from the plant material. Subsequently the cultures were studied for production of bioactive compounds. One of the isolated strains showed interesting antimicrobial activities in a preliminary screening, and was selected for taxonomic identification, as well as for characterization of its active principles. The present paper is dedicated to the presentation of these results.

\section{Experimental section}

\subsection{General experimental procedures}

HPLC-DAD-MS analysis was performed using an amaZon speed ETD ion trap mass spectrometer (Bruker Daltonics) in positive and negative ionization modes. The mass spectrometer was coupled to an DIONEX UltiMate 3000 Diode Array Detector [column 2.1 $\times 50 \mathrm{~mm}, 1.7 \mu \mathrm{m}, \mathrm{C} 18$ Acquity UPLC BEH (Waters), solvent $\mathrm{A}: \mathrm{H}_{2} \mathrm{O}+0.1 \%$ formic acid; solvent $\mathrm{B}$ : acetonitrile $(\mathrm{ACN})+0.1 \%$ formic acid, gradient: $5 \% \mathrm{~B}$ for $0.5 \mathrm{~min}$, increasing to $100 \% \mathrm{~B}$ in $20 \mathrm{~min}$, maintaining isocratic conditions at $100 \% \mathrm{~B}$ for $10 \mathrm{~min}$, flow $=0.6$ $\mathrm{mL} / \mathrm{min}, \mathrm{UV}$-vis detection 200-600 nm]. HRESIMS mass spectra were obtained with a maXis ESI TOF mass spectrometer (Bruker Daltonics) [scan range m/z 100-2500, rate $2 \mathrm{~Hz}$, capillary voltage $4500 \mathrm{~V}$, dry temperature $200^{\circ} \mathrm{C}$ ], coupled to an Agilent 1200 series HPLCUV system [column $2.1 \times 50 \mathrm{~mm}, 1.7 \mu \mathrm{m}, \mathrm{C}_{18}$ Acquity UPLC BEH (Waters), solvent A: $\mathrm{H}_{2} \mathrm{O}$ $+0.1 \%$ formic acid; solvent $\mathrm{B}: \mathrm{ACN}+0.1 \%$ formic acid, gradient: $5 \% \mathrm{~B}$ for $0.5 \mathrm{~min}$, increasing to $100 \% \mathrm{~B}$ in $19.5 \mathrm{~min}$, maintaining $100 \% \mathrm{~B}$ for $5 \mathrm{~min}, \mathrm{R}_{\mathrm{F}}=0.6 \mathrm{mLmin}^{-1}, \mathrm{UV}-\mathrm{vis}$ detection 200-600 nm]. The molecular formulas were calculated including the isotopic pattern (Smart Formula algorithm). The separation was performed at room temperature on an 
Agilent 1100 series preparative HPLC system [ChemStation software (Rev. B.04.03 SP1); binary pump system; column: Kinetex 5u RP C18, dimensions $250 \times \mathrm{mm}$; mobile phase: $\mathrm{ACN}+0.05 \%$ trifluoroacetic acid (TFA) and water $+0.05 \%$ TFA; flow rate $20 \mathrm{~mL} / \mathrm{min}$; diode-array UV detector; 226 fraction collector]. 1D and 2D NMR spectra were recorded at $24.8{ }^{\circ} \mathrm{C}$ on a Bruker $500 \mathrm{MHz}$ Avance III spectrometer with a BBFO (plus) SmartProbe $\left({ }^{1} \mathrm{H}\right.$ $500 \mathrm{MHz},{ }^{13} \mathrm{C} 125 \mathrm{MHz}$ ). Chemical shifts are given in parts per million (ppm), and coupling constants in hertz $(\mathrm{Hz})$. Spectra were referenced to residual solvent signals with resonances at $\delta_{\mathrm{H}} / \mathrm{c} 3.31 / 49.15$ for $\mathrm{MeOH}-d_{4}$. Optical rotations were determined using an Anton Paar MCP 150 polarimeter (sodium D line, a Nickel alloy sample cell $100 \mathrm{~mm} / 3 \mathrm{~mm}, 0.7 \mathrm{~mL}$ volume), UV spectra were recorded using a Shimadzu UV-vis spectrophotometer UV-2450. ), CD spectra were recorded on a JASCO spectropolarimeter, model J-815 using $0.5 \mathrm{~mm}$ quartz cuvette and $\mathrm{MeOH}$ as solvent.

\subsection{Fungal material and morphological analysis}

During a survey on endophytic fungi of forest trees, in September 2016, symptomless shoots and healthy 2-3 years old shoots were collected from English Yew (Taxus baccata) in Arasbaran region, northwestern zone of Iran. For the isolation of endophytes, $15-20 \mathrm{~cm}$ length shoots were sterilized for 45-60 seconds in 70\% ethanol, then $10 \mathrm{~min}$ in 3\% sodium hypochloride $(\mathrm{NaClO})$ and 30 seconds in $70 \%$ ethanol. They were then dried on sterile filter paper under clean bench. Small segments were cut and transferred on Malt Extract Agar (MEA) plate supplemented with $100 \mathrm{mg} / \mathrm{L}$ streptomycin sulphate and $100 \mathrm{mg} / \mathrm{L}$ ampicillin. Purification was conducted by hyphal tip technique. Cultures were preserved on MEA (malt extract agar) in $2 \mathrm{ml}$ microtube slants at $4^{\circ} \mathrm{C}$ in the University of Tabriz Culture Collection (CCTU). Cultural characteristics of Chaetosphaeronema achilleae including colony characters and pigments production, shape, and growth rate and microscopic characteristics including dimensions of conidiomata, conidiophores, conidiogenous cells and conidia were recorded on PDA, OA and MEA, according to previously reported conditions (Hyde et al., 2016).

\subsection{Molecular analysis, sequencing and phylogenetic analysis}

Genomic DNA was extracted from 7 days old culture grown on MEA. Fresh fungal mycelia were harvested and subjected to DNA extraction using the EZ-10 Spin Column Genomic DNA Miniprep kit (Bio Basic Canada Inc., Markham, Ontario, Canada) following the manufacturer's protocol. Molecular analysis was carried out using sequence data of internal 
transcribed spacer (ITS) regions and partial large nuclear ribosomal RNA subunit (nrLSU) region. ITS-rDNA fragment was amplified using ITS1F/ITS4 primer (White et al., 1990). The partial large nuclear ribosomal RNA subunit (nrLSU) region was amplified using primers LROR/LR5 (Vilgalys and Hester, 1990). The amplicons were sequenced in both directions using the same primer set. Sequence files were edited using SeqMan software in the Lasergene package (DNASTAR Inc., Madison, WI, USA) and consensus sequence was computed using the forward and reverse sequences. The consensus sequence was compared with sequences in the GenBank using the basic local alignment search tool (BLAST). Sequences were deposited in GenBank with the accession numbers MN422624 and MN422698 for ITS and LSU, respectively. ITS-rDNA and LSU gene sequence data for reference strain sequences were downloaded from GenBank and included in alignment files. Bayesian analyses were accomplished according to previously published procedure (Narmani et al. 2018).

\subsection{Fermentation and extraction}

A $500 \mathrm{~mL}$ Erlenmeyer flask containing $200 \mathrm{~mL}$ of YMG medium consisting of $1.0 \%$ malt extract, $0.4 \%$ glucose, $0.4 \%$ yeast extract, $\mathrm{pH} 6.3$ was inoculated with five $7 \mathrm{~mm}$ agar disks of a well-grown agar culture of $C$. achilleae and incubated at $23{ }^{\circ} \mathrm{C}$. Well-grown mycelial mass was homogenized using a Heidolph Silent Crusher, then 30 other flasks containing the same medium composition were inoculated using $2 \mathrm{~mL}$ of homogenized culture. The flasks were incubated at $23{ }^{\circ} \mathrm{C}$ under constant shaking at $140 \mathrm{rpm}$ on a rotary shaker. Six days after the sugar was used up, fungal mycelia was harvested by filtration, and the supernatant was treated with 3\% adsorber resin Amberlite XAD-16N over $4 \mathrm{~h}$ on magnetic stirrers for stirring at room temperature. Then, XAD was extracted using acetone and after evaporation, the residual aqueous phase was extracted three times using ethyl acetate. The ethyl acetate fraction was dried over anhydrous $\mathrm{Na}_{2} \mathrm{SO}_{4}$, filtered and concentrated under vacuum to yield $2242 \mathrm{mg}$ of crude extract. The wet mycelia were extracted three times with acetone, and further extracted with methanol in an ultrasonic bath at $40^{\circ} \mathrm{C}$ for $30 \mathrm{~min}$. The resulting solution was evaporated to yield an aqueous phase, which was extracted three times with ethyl acetate. After drying over anhydrous $\mathrm{Na}_{2} \mathrm{SO}_{4}$, the ethyl acetate fraction was concentrated under vacuum to yield $671 \mathrm{mg}$ of crude extract.

\subsection{Isolation of compounds 1-7}


Separation of crude supernatant extract $(500 \mathrm{mg}$ ) was achieved by preparative HPLC (5 runs( using a linear gradient of solvent B from $7 \%$ to $25 \%$ solvent B in $45 \mathrm{~min}, 30$ to $100 \%$ B in 5 min, followed by $100 \%$ B for $10 \mathrm{~min}$ at a flow rate of $20 \mathrm{~mL} / \mathrm{min}$. Solvant B was constituted of acetonitrile $(\mathrm{ACN})+0.05 \%$ trifluoroacetic acid (TFA) while solvent A was constituted of $\mathrm{H}_{2} \mathrm{O}+0.05 \%$ TFA. The fractions were combined according to UV absorption at 220, 280, and $350 \mathrm{~nm}$ and concurrent HPLC-MS analyses. The fractionation yielded seven pure compounds: $2(2.97 \mathrm{mg})$ at a retention time $\left(t_{\mathrm{R}}\right)=8.5 \mathrm{~min}, \mathbf{1}(6.71 \mathrm{mg})$ at $t_{\mathrm{R}}=12.75 \mathrm{~min}, \mathbf{3}$ $(10.64 \mathrm{mg})$ at $t_{\mathrm{R}}=15.71 \mathrm{~min}, 4(54.97 \mathrm{mg})$ at $t_{\mathrm{R}}=17.01 \mathrm{~min}, 7(4.15 \mathrm{mg})$ at $t_{\mathrm{R}}=23.82 \mathrm{~min}, 5$ $(47.42 \mathrm{mg})$ at $t_{\mathrm{R}}=28.2 \mathrm{~min}$, and $6(209.95 \mathrm{mg})$ at $t_{\mathrm{R}}=35.52 \mathrm{~min}$.

Chaetosisoindolinone (1): White gum; $[\alpha]^{20}{ }_{\mathrm{D}}-30.0$ (c 0.35, MeOH; UV (MeOH, $c \quad 0.1$ $\mathrm{mg} / \mathrm{mL}) \lambda_{\max }(\log \varepsilon) 270$ (3.73), 228 (3.90) nm; CD (c $\left.1 \mathrm{mg} / \mathrm{mL}, \mathrm{MeOH}\right), \lambda_{\max } \mathrm{nm}(\mathrm{CD}) 200$ (+21); HR-ESIMS $m / z 210.0757[\mathrm{M}+\mathrm{H}]^{+}\left(\right.$Calcd for $\left.\mathrm{C}_{10} \mathrm{H}_{12} \mathrm{NO}_{4}{ }^{+}, 210.0755\right), \mathrm{m} / z 232.0574 \quad[\mathrm{M}+$ $\mathrm{Na}]^{+}$(Calcd for $\mathrm{C}_{10} \mathrm{H}_{11} \mathrm{NO}_{4} \mathrm{Na}^{+}: 232.0580$ ); ${ }^{1} \mathrm{H}$ NMR (Methanol $d_{4}, 500 \mathrm{MHz}$ ) and ${ }^{13} \mathrm{C} \mathrm{NMR}$ (Methanol $d_{4}, 125 \mathrm{MHz}$ ) data, see Table 1.

Chaetosindanone (2): White gum; $[\alpha]^{20}{ }_{\mathrm{D}}+4.0(c$ 0.1, $\mathrm{MeOH}) ; \mathrm{UV}(\mathrm{MeOH}, c 0.1 \mathrm{mg} / \mathrm{mL})$ $\lambda_{\max }(\log \varepsilon) 270$ (3.61), 221 (3.73), 203 (3.67) nm; HR-ESIMS m/z $211.0599[\mathrm{M}+\mathrm{H}]^{+}$(Calcd for $\mathrm{C}_{10} \mathrm{H}_{11} \mathrm{O}_{5}^{+}: 211.0601$ ), $m / z 233.0417[\mathrm{M}+\mathrm{Na}]^{+}$(Calcd for $\mathrm{C}_{10} \mathrm{H}_{10} \mathrm{O}_{5} \mathrm{Na}^{+}: 233.0420$ ); ${ }^{1} \mathrm{H}$ NMR (Methanol $d_{4}, 500 \mathrm{MHz}$ ) and ${ }^{13} \mathrm{C}$ NMR (Methanol $d_{4}, 125 \mathrm{MHz}$ ) data, see Table 1 .

\subsection{Biological activities}

Antimicrobial activities (Minimum inhibitory concentrations; MICs) of the isolated metabolites were determined using a serial dilution assay against Bacillus subtilis DSM 10, Chromobacterium violaceum DSM 30191, Escherichia coli DSM 1116, Micrococcus luteus DSM 1790, Pseudomonas aeruginosa DSM PA14, Staphylococcus aureus DSM 346, Candida albicans DSM 1665, Mucor hiemalis DSM 2656, Pichia anomala DSM 6766, Rhodoturula glutinis DSM 10134, Schizosaccharomyces pombe DSM 70572 and Mycobacterium smegmatis DSM ATCC700084 according to previously described protocols (Richter et al., 2016). The in vitro cytotoxicity assay was performed with some cancer cells including the mouse fibroblast cell line L929, cervix carcinoma cell line KB-3-1, human breast adenocarcinoma MCF-7, human prostate cancer PC-3, squamous carcinoma A431, human lung carcinoma A549 and ovarian carcinoma SKOV-3 as previously described (Sandargo et al., 2018). The inhibition of biofilm formation against Staphylococcus aureus DSM 1104 was tested in 96-well tissue microtiter plates (TPP, Trasadingen, Switzerland) 
following the protocol of Yuyama et al. (2017). The compounds were tested in concentrations of up to $256 \mu \mathrm{g} / \mathrm{mL}$. $\mathrm{MeOH}$ and cytochalasin B were used as negative and positive control, respectively (Phukhamsakda et al., 2018; Yuyama et al., 2018).

\section{Results and discussion}

Preparative RP-HPLC purification of extracts from the culture of the plant associated fungus Chaetosphaeronema achilleae led to the isolation and structure elucidation of 7 secondary metabolites including a previously unreported isoindolinone and a previously undescribed indanone derivative.

\subsection{Structure elucidation}

The molecular formula of compound $\mathbf{1}$, isolated as white gum, was deduced to be $\mathrm{C}_{10} \mathrm{H}_{11} \mathrm{NO}_{4}$ on the basis of the HRESIMS which exhibited ion clusters at $\mathrm{m} / z 210.0757[\mathrm{M}+$ $\mathrm{H}]^{+}\left(\right.$Calcd for $\mathrm{C}_{10} \mathrm{H}_{12} \mathrm{NO}_{4}{ }^{+}$: 210.0755), $232.0574 \quad[\mathrm{M}+\mathrm{Na}]^{+}\left(\right.$Calcd for $\mathrm{C}_{10} \mathrm{H}_{11} \mathrm{NO}_{4} \mathrm{Na}^{+}$: 232.0580) and 441.1265 $[2 \mathrm{M}+\mathrm{Na}]^{+}$. The ${ }^{1} \mathrm{H}$ NMR spectrum (Table 1) showed signals for an aromatic proton at $\delta_{\mathrm{H}} 6.89(\mathrm{~s}, \mathrm{H}-7)$, a methine proton at $\delta_{\mathrm{H}} 4.61((\mathrm{q}, J=6.6 \mathrm{~Hz}, \mathrm{H}-3)$, a methoxy group at $\delta_{\mathrm{H}} 3.90\left(\mathrm{~s}, 6-\mathrm{OCH}_{3}\right)$ as well as a methyl doublet at $\delta_{\mathrm{H}} 1.47(\mathrm{~d}, J=6.6 \mathrm{~Hz}$, $\mathrm{H}-8$ ). The ${ }^{13} \mathrm{C}$ NMR spectrum of 1 (Table 1) showed 10 signals including those of an amide carbonyl at $\delta_{\mathrm{C}} 173.6(\mathrm{C}-1)$ and a pentasubstituted benzene ring. The remaining signals were due to a methine carbon at $\delta_{\mathrm{C}} 52.7(\mathrm{C}-3)$, a methyl at $\delta_{\mathrm{C}} 19.2(\mathrm{C}-8)$ and a methoxy group at $\delta_{\mathrm{C}}$ $56.9\left(6-\mathrm{OCH}_{3}\right)$. Careful analysis of ${ }^{1} \mathrm{H}$ and ${ }^{13} \mathrm{C}$ NMR, ${ }^{1} \mathrm{H}-{ }^{1} \mathrm{H}$ COSY, HSQC and HMBC spectra revealed that compound 1 was related to isoindolinones (Wittstein et al., 2016). This was confirmed by HMBC correlations (Table 1) from the proton H-7 to C-1, C-3a, C-5, C-6, and $\mathrm{C}-7 \mathrm{a}$; and from the proton $\mathrm{H}-3$ to $\mathrm{C}-1, \mathrm{C}-3 \mathrm{a}, \mathrm{C}-4$, and $\mathrm{C}-8$. The location of the methoxy group was evidenced by the HMBC correlation from the protons at $\delta_{\mathrm{H}} 3.90\left(\mathrm{~s}, 6-\mathrm{OCH}_{3}\right)$ to the carbon at $\delta_{\mathrm{C}} 150.6(\mathrm{C}-6)$. The configuration at C-3 was proposed to be $R$ based on the comparison of the positive optical rotation of $\mathbf{1}\left([\alpha]^{20}{ }_{\mathrm{D}}-30.0(c 0.35, \mathrm{MeOH})\right.$ with those of its congeners (3R)-5,7-dihydroxy-3-methylisoindolin-1-one $\left([\alpha]^{20}{ }_{\mathrm{D}}+18.1(c\right.$ 0.1, MeOH$\left.)\right)(\mathrm{El}$ Amrani et al., 2012) and (3S)-methyl-2,3-dihydro-1H-isoindolin-1-one $\left([\alpha]^{20}{ }_{\mathrm{D}}-34.0(c 0.26\right.$, Dichloromethane)) (Comins et al., 2005). Furthermore, the positive Cotton effect observed in at $200 \mathrm{~nm}$ region of the electronic circular dichroism (ECD) curves of compound 1 (Fig. S10) were related to the ECD spectra of mariline $\mathrm{A}_{2}$ ( $S$-configuration at C-3) and opposite to those of mariline $\mathrm{A}_{1}(R$-configuration at $\mathrm{C}-3)$ and thus confirmed the $R$ configuration (cf. Almeida et al., 2012). The structure of metabolite 1 was thus elucidated as (3S)-4,5-dihydroxy-3methyl-6-methoxyisoindolin-1-one to which the trivial name chaetosisoindolinone was given. 
The HRESIMS of compound $\mathbf{2}$ also isolated as a white gum showed ion clusters at $\mathrm{m} /$ $z 211.0599[\mathrm{M}+\mathrm{H}]^{+}$and $233.0417[\mathrm{M}+\mathrm{Na}]^{+}$consistent with the molecular formula $\mathrm{C}_{10} \mathrm{H}_{10} \mathrm{O}_{5}$ (Calcd for $\mathrm{C}_{10} \mathrm{H}_{11} \mathrm{O}_{5}^{+}:$211.0601; Calcd for $\mathrm{C}_{10} \mathrm{H}_{10} \mathrm{O}_{5} \mathrm{Na}^{+}:$233.0420). Its ${ }^{1} \mathrm{H}$ NMR spectrum showed in addition to the aromatic proton resonance at $\delta_{\mathrm{H}} 6.82(\mathrm{~s}, \mathrm{H}-4)$ signals attributed an oxymethine proton at $\delta_{\mathrm{H}} 5.22(\mathrm{dd}, J=6.3,2.3 \mathrm{~Hz}, \mathrm{H}-3)$, a methoxy group at $\delta_{\mathrm{H}} 3.97$ (s, 5$\left.\mathrm{OCH}_{3}\right)$ and a methylene group at $\delta_{\mathrm{H}} 2.46(\mathrm{brd}, J=18.0 \mathrm{~Hz}, \mathrm{H}-2 \mathrm{a})$ and $3.02(\mathrm{dd}, J=18.0,6.3$ $\mathrm{Hz}, \mathrm{H}-2 \mathrm{~b}$ ). The ${ }^{13} \mathrm{C}$ NMR spectrum displayed 10 carbon signals (Table 1) including a carbonyl at $\delta_{\mathrm{C}} 205.5(\mathrm{C}-1)$, six aromatic carbons at at $\delta_{\mathrm{C}} 135.1$ (C-3a), $101.2(\mathrm{C}-4), 157.2$ (C5), 144.8 (C-6), $149.8(\mathrm{C}-7)$, and $118.4(\mathrm{C}-7 \mathrm{a})$. The remaining signals were attributed to a methylene at $\delta_{\mathrm{C}} 48.4(\mathrm{C}-2)$, a hydroxymethine at $\delta_{\mathrm{C}} 69.1(\mathrm{C}-3)$ and a methoxy group at $\delta_{\mathrm{C}}$ $57.0\left(5-\mathrm{OCH}_{3}\right)$. These spectral data suggested 2 to be an indanone derivative (Okpekon et al., 2009; Rukachaisirikul et al., 2013). Assignment of all the proton and carbon signals was achieved by careful examination of the ${ }^{1} \mathrm{H}-{ }^{1} \mathrm{H}$ COSY, HSQC and HMBC spectra. In the HMBC spectrum, some important correlations were depicted from the proton at $\mathrm{H}-3$ to $\mathrm{C}-1$, $\mathrm{C}-3 \mathrm{a}$, and C-4, as well as from the proton at H-4 to C-3a, C-5, C-6, and C-7a (Fig. 2). The location of the methoxyl group was evidenced by the correlation observed between its protons at $\delta_{\mathrm{H}} 3.97\left(\mathrm{~s}, 5-\mathrm{OCH}_{3}\right)$ and the carbon at $\delta_{\mathrm{C}} 157.2(\mathrm{C}-5)$. The configuration at C-3 was proposed to be $S$ based on the positive optical rotation of compound $2\left([\alpha]^{20}{ }_{\mathrm{D}}+4.0\right.$ (c 0.1 , $\mathrm{MeOH}))$ in comparison to that of the related compound claulansine $\mathrm{E}\left([\alpha]^{20}{ }_{\mathrm{D}}+3.6(c 0.1\right.$, $\mathrm{MeOH})$ ) (Liu et al., 2012). The structure of 2 was finally concluded as (3S)-3,6,7-trihydroxy5-methoxy-1-indanone trivially named chaetosindanone.

The isolated known compounds were identified based on comparison of their spectral data with literature as follow: 2-(2-acetyl-3,5-dihydroxyphenyl)acetic acid (3), previously isolated from Mucor sp (Feng et al., 2014); vulculic acid (4), previously obtained from Penicillium sp (Kimura et al., 1991); 2-(2-acetyl-3-hydroxy-5-methoxyphenyl)acetic acid (5) also produced by Mucor sp (Feng et al., 2014); curvulin (6) was previously reported from a Paraphoma sp. isolated from Cirsium arvense (Poluektova et al., 2018), and curvulol (7), a metabolite of Curvularia siddiqui (Kamal et al., 1963).

Compound $\mathbf{1}$ is an isoindolinone, a rare class of secondary metabolites characterized by a bicylic nucleus derived from fusion of a benzene ring and a $\gamma$-lactam. One of its congeners namely (3S)-methyl-2,3-dihydro-1H-isoindolin-1-one was recently isolated from an unidentified endophytic fungus obtained from the inner tissues of healthy leaves of the mangrove plant Avicennia marina from Oman (El Amrani et al., 2012). Metabolite 2 bearing 
a hydroxycyclopentenone ring is related to the polyketides cyclomarinone produced by the marine sponge-derived fungus Stachylidium sp (Almeida et al., 2012), 3-methoxyindanone isolated from the marine cyanobacterium Lyngbya majuscule (Nagle et al., 2000), the dichlorinated indanone tripartin obtained from the culture broth of the Streptomyces sp. associated with a larva of the dung beetle Copris tripartitus Waterhouse (Kim et al., 2013) and to the carbazole alkaloid claulansine E from the stems of Clausena lansium (Liu et al., 2012). Biosynthetically, the structures of the isolated polyketides are related and may have arisen from 6-ethyl-2,4-dihydroxybenzoic acid (8) resulting from the condensation of one propionyl-CoA unit with three acetyl-CoA units followed by cyclisation (Almeida et al., 2012; El Maddah et al., 2019) (Scheme 1). The oxidation of this intermediate followed by incorporation of a methyl group would lead to 2-(2-acetyl-3,5-dihydroxyphenyl) acetic acid (3). The $O$-methylation of metabolite 3 could afford 2-(2-acetyl-3-hydroxy-5methoxyphenyl)acetic acid (5) while its acetylation yields curvulin (6). Vulculic acid (4) could be obtained by the hydroxylation of compound 5. Oxidative scission of vulculic acid (4) could afford the reactive intermediate 9 from which chaetosindanone (2) could be obtained by an aldol reaction. Reduction of the two carbonyl groups present in compound 9 followed by the etherification reaction could yield curvulol (7). Reduction of the ketone group present in $\mathbf{9}$ gives the reactive intermediate $\mathbf{1 0}$ which could undergo lactamization through the amino acid metabolism to form the phthalimidine core present in compound $\mathbf{1}$ (Yunus et al., 2016; El Maddah et al., 2019).

\section{Biological activities}

Compounds 2, 4 and 7 showed moderate to weak antifungal activity against Mucor hiemalis DSM 2656 and antibacterial activity against Staphylococcus aureus DSM 346 and Bacillus subtilis DSM 10, respectively, with a MIC value of $33.33 \mu \mathrm{g} / \mathrm{mL}$ (Table 2). Compounds $\mathbf{1}, \mathbf{2}$, 4 and 7 showed significant cytotoxicity against the mouse fibroblast cell line L929 and the cervix carcinoma cell line $\mathrm{KB}-3-1$, with $\mathrm{IC}_{50}$ values ranging from 4.3 to $23 \mu \mathrm{g} / \mathrm{mL}$ while in the case of compounds $\mathbf{3}, \mathbf{5}$ and $\mathbf{6}$, no significant effects were observed. Compound $\mathbf{2}$ showed the strongest cytotoxicity among the metabolites tested against human breast adenocarcinoma MCF-7 cells with $\mathrm{IC}_{50}$ value of $1.5 \mu \mathrm{g} / \mathrm{mL}$ (Table 3). In the Staphylococcus aureus biofilm inhibition assay, Minimum Inhibitory Concentration (MIC) values of 256, 64 and $64 \mu \mathrm{g} / \mathrm{mL}$ were observed for metabolites 2, $\mathbf{4}$ and 7, respectively. Moreover, compound $\mathbf{4}$ showed a strong inhibition of biofilm formation of $96.82 \%$ and $91.95 \%$ at 256 and $128 \mu \mathrm{g} / \mathrm{mL}$, 
respectively. Compound 7 also exhibited a strong inhibition of biofilm formation of $96.18 \%$ at $256 \mu \mathrm{g} / \mathrm{mL}$. In the case of compound 1, 3, 5 and 6 MIC values were not obtained. This means that these compounds were not toxic against planktonic cells at the tested concentrations, but they were able to prevent biofilm formation even at lower concentrations ( 8 and $4 \mu \mathrm{g} / \mathrm{mL}$ ) (Table 4). Biofilm formation is an important factor associated with drug resistance, which made it difficult to eradicate microbial infection. To overcome this problem, the need for new and efficient anti-biofilm agents is felt more than ever, as they could be used in combination therapy with classical antibiotics (Estrela and Abraham, 2016; Hyde et al., 2019). Notably, compounds with biofilms dispersing feature are rare. Recently, we reported two new heptanedioic acid derivatives, four prenylated $p$-terphenyl quinones and microporenic acids A-G with strong activities on both biofilm formaton and dispersion in Staphylococcus aureus (Narmani et al., 2019; Chepkirui et al., 2018).

\section{Acknowledgements}

The Ministry of Science, Research and Technology (MSRT) of Iran, the Iranian Mycological Society ( $\mathrm{PhD}$ stipend to A.N.) and the Alexander von Humboldt Foundation (postdoc stipends to R.B.T. and S.E.H.) are gratefully acknowledged for their financial support. We are grateful to Christel Kakoschke, Sabrina Karwehl, Cäcilia Bergmann, Vanessa Stiller and Wera Collisi for recording NMR spectra and for expert technical assistance, respectively.

\section{Supplementary data}

Supplementary data associated with this article can be found in the online version at

\section{References}

1. Almeida, C., Hemberger, Y., Schmitt, S.M., Bouhired, S., Natesan, L., Kehraus, S., Dimas, K., Gütschow, M., Bringmann, G., König, G.M., 2012. Marilines A-C: Novel phthalimidines from the sponge-derived fungus Stachylidium sp. Chem. Eur. J. 18, 8827-8834. Doi: 10.1002/chem.201103278.

2. Bills, G.F., Gloer, J.B., 2016. Biologically active secondary metabolites from the fungi Microbiol. Spectr. 4. Doi: 10:1128/microbiolspec.FUNK-0009-2016.

3. Chepkirui, C., Yuyama, K., Wanga, L., Decock, C., Matasyoh, J., Abraham, W.R., Stadler, M., 2018. Microporenic acids A-G, biofilm inhibitors and antimicrobial 
agents from the basidiomycete Microporus sp. J. Nat. Prod. 81, 778-784. Doi: 10.1021/acs.jnatprod.7b00764.

4. Comins, D.L., Schilling S., Zhang Y., 2005. Asymmetric synthesis of 3-substituted isoindolinones: Application to the total synthesis of (+)-lennoxamine. Org. Lett. 7, 95-98. https://doi.org/10.1021/o1047824w.

5. El Amrani, M., Debbab, A., Aly, A.H., Wray, V., Dobretsov, S., Müller, W.E.G., Lin, W., Daowan Lai, D., Proksch, P., 2012. Farinomalein derivatives from an unidentified endophytic fungus isolated from the mangrove plant Avicennia marina. Tetrahedron Lett. 53, 6721-6724. https://doi.org/10.1016/j.tetlet.2012.10.011.

6. El Maddah, F., Eguereva, E., Kehraus, S., Köni, G.M., 2019. Biosynthetic studies of novel polyketides from the marine sponge derived fungus Stachylidium sp. 293K04. Org. Biomol. Chem. DOI: 10.1039/C9OB00198K.

7. Estrela, A.B., Abraham, W.R., 2016. Fungal metabolites for the control of biofilm infections. Agriculture 6,37-62. https://doi.org/10.3390/agriculture6030037.

8. Feng C.-C., Chen G.-D., Zhao Y.-Q., Xin S.-C., Li S., Tang J.-S., Li X.-X., Hu D., Liu X.-Z., Gao H., 2014. New isocoumarins from a cold-adapted fungal strain Mucor sp. and their developmental toxicity to zebrafish embryos. Chem. Biodivers. 11, 1099-1108. Doi: 10.1002/cbdv.201400005.

9. Hyde, K.D., Hongsanan, S., Jeewon, R., Bhat, D.J., McKenzie, E.H.C., et al. 2016. Fungal diversity notes 367-490: taxonomic and phylogenetic contributions to fungal taxa. Fungal Divers. 80, 1-270. https://doi.org/10.1007/s13225-016-0373-x.

10. Hyde, K.D., Xu, J.C., Rapior, S., Jeewon, R., Lumyong, S., Niego, A.G.T. et al. 2019. The amazing potential of fungi, 50 ways we can exploit fungi industrially. Fungal Divers. 97, 1-136

11. Kamal, A., Khan, M.A., Qureshi, A.A., 1963. Studies in the biochemistry of microorganisms II : Constitution of curvulin, curvulinic acid and curvulol, metabolic products of Curvularia siddiqui. Tetrahedron 19, 111-115. https://doi.org/10.1016/0040-4020(63)80011-3.

12. Kim, S.-H., Kwon, S.H., Park, S.-H., Lee, J.K., Bang, H.-S., Nam, S.J., Kwon, H.C., Shin, J., Oh, D-C., 2013. Tripartin, a histone demethylase inhibitor from a bacterium associated with a dung beetle larva. Org. Lett. 15, 1834-1837. Doi: $10.1021 / \mathrm{ol} 4004417$. 
13. Kimura, Y., Nishibe, M., Nakajima, H., Hamasaki, T., 1991. Vulculic acid, a pollen germination Inhibitor produced by the fungus, Penicillium sp. Agric. Biol. Chem. 55, 1137-1138. https://doi.org/10.1080/00021369.1991.10870695.

14. Liu, H., Li, C.-J., Yang, J.-Z., Ning,N., Si, Y.-K., Li, L., Chen,N.-H., Zhao, Q., Zhang D.-M., 2012. Carbazole alkaloids from the stems of Clausena lansium. J. Nat. Prod. 75, 677-682. Doi: 10.1021/np200919a.

15. Nagle, D.G., Zhou, Y.-D., Park, P.U., Paul, V.J., Rajbhandari, I., Duncan, C.J.G., Pasco, D.S., 2000. A new indanone from the marine cyanobacterium Lyngbya majuscula that inhibits hypoxia-induced activation of the VEGF promoter in Hep3B Cells. J. Nat. Prod. 63, 1431-1433. https://doi.org/10.1021/np000216e.

16. Narmani, A., Teponno, R. B., Arzanlou, M., Surup, F., Helaly, S. E., Wittstein, K., Praditya, D. F., Babai-Ahari, A., Steinmann, E., Stadler, M. 2019. Cytotoxic, antimicrobial and antiviral secondary metabolites produced by the plant pathogenic fungus Cytospora sp. CCTU A309. Fitoterapia 134, 314-322. https://doi.org/10.1016/ j.fitote.2019.02.015.

17. Narmani, A., Pichai, S., Palani, P., Arzanlou, M., Surup, F., Stadler, M., 2018. Daldinia sacchari (Hypoxylaceae) from India produces the new cytochalasins Saccalasins A and B and belongs to the D. eschscholtzii species complex. Mycol. Prog. 18, 175-185. https://doi.org/10.1007/s11557-018-1413-6.

18. Okpekon, T., Millot, M., Champy, P., Gleye, C., Yolou, S., Bories, C., Loiseau, P., Laurens, A., Hocquemiller, R., 2009. A novel 1-indanone isolated from Uvaria afzelii roots. Nat. Prod. Res. 23, 909-915. Doi: 10.1080/14786410802497240.

19. Phukhamsakda, C., Macabeo, A.P.G., Yuyama, K., Hyde, K.D., Stadler, M., 2018. Biofilm inhibitory abscisic acid derivatives from the plant-associated Dothideomycete fungus Roussoella sp. Molecules 23, 2190. https://doi.org/10.3390/molecules23092190.

20. Poluektova, E., Tokarev , Y., Sokornova, S., Chisty, L., Evidente, A., Berestetskiy, A., 2018. Curvulin and phaeosphaeride A from Paraphoma sp. VIZR 1.46 isolated from Cirsium arvense as potential herbicides. Molecules 23, 2795-2810. Doi:10.3390/molecules23112795.

21. Richter, C., Helaly, S.E., Thongbai, B., Hyde, K.D., Stadler, M., 2016. Pyristriatins A and B: Pyridino-cyathane antibiotics from the basidiomycete Cyathus cf. striatus. J. Nat. Prod. 79, 1684-1688. Doi: 10.1021/acs.jnatprod.6b00194. 
22. Rukachaisirikul, V., Buadam, S., Sukpondma, Y., Phongpaichit, S., Sakayaroj, J., Hutadilok-Towatana, N., 2013. Indanone and mellein derivatives from the Garciniaderived fungus Xylaria sp. PSU-G12. Phytochem. Lett. 6, 135-138. http://dx.doi.org/ 10.1016/j.phytol.2012.11.007.

23. Sandargo, B., Thongbai, B., Stadler, M., Surup, F., 2018. Cysteine-derived pleurotin congeners from the nematode-trapping basidiomycete Hohenbuehelia grisea. J. Nat. Prod. 81, 286-291. Doi: 10.1021/acs.jnatprod.7b00713.

24. Vilgalys, R., Hester, M., 1990. Rapid genetic identification andmapping of enzymatically amplified ribosomal DNA from several Cryptococcus species. J. Bacteriol. 172, 4238-4246. Doi: 10.1128/jb.172.8.4238-4246.1990.

25. White, T.J., Bruns,T., Lee, S., Taylor, J.W., 1990. Amplification and direct sequencing of fungal ribosomal RNA genes for phylogenetics. In Innis, M.A., Gelfand, D.H., Sninsky, J.J., White, T.J., (Eds.), PCR protocols: A guide to methods and applications. Academic Press, Inc., New York, pp. 315-322.

26. Wittstein, K., Rascher, M., Rupcic, Z., Löwen, E., Winter, B., Köster, R.W., Stadler, M., 2016. Corallocins A-C, Nerve Growth and Brain-Derived Neurotrophic Factor inducing metabolites from the mushroom Hericium coralloides. J. Nat. Prod. 79, 2264-2269. Doi: 10.1021/acs.jnatprod.6b00371.

27. Yunus, I.S., Liu, Y.-C., Nakamura, Y., 2016. The importance of serine decarboxylase 1 (SDC1) and ethanolamine biosynthesis during embryogenesis of Arabidopsis thaliana. Plant J. 88, 559-569. https://doi.org/10.1111/tpj.13278.

28. Yuyama, K.T., Neves, T.S.P.C., Memória, M.T., Tartuci, I.T., Abraham, W., 2017. Aurantiogliocladin inhibits biofilm formation at subtoxic concentrations. AIMS Microbiol, 3, 50-60. Doi: 10.3934/microbiol.2017.1.50.

29. Yuyama, K.T., Wendt, L., Surup, F., Kretz, R., Chepkirui, C., Wittstein, K., Boonlarppradab, C., Wongkanoun, S., Luangsa-ard, J.J., Stadler, M., Abraham, W.R., 2018. Cytochalasans act as inhibitors of biofilm formation of Staphylococcus aureus. Biomolecules 8, 129. Doi: 10.3390/biom8040129. 
<smiles>COc1cc2c(c(O)c1O)[C@H](C)NC2=O</smiles><smiles>COc1cc2c(c(O)c1O)C(=O)CC2O</smiles><smiles>[R6]OC(=O)Cc1cc(O[R10])c([R2])c(O)c1C(C)=O</smiles>

$\begin{array}{lll}\mathrm{R}_{1} & \mathrm{R}_{2} & \mathrm{R}_{3}\end{array}$ $\begin{array}{llll}3 & \mathrm{H} & \mathrm{H} & \mathrm{H}\end{array}$ $4 \mathrm{CH}_{3} \quad \mathrm{OH} \quad \mathrm{H}$ $5 \mathrm{CH}_{3} \quad \mathrm{H} \quad \mathrm{H}$ $6 \quad \mathrm{H} \quad \mathrm{H} \quad \mathrm{CH}_{2} \mathrm{CH}_{3}$<smiles>COc1cc2c(c(O)c1O)[C@H](C)OC2</smiles>
7

Fig.1. Structures of compounds 1-7 isolated from Chaetosphaeronema achilleae.

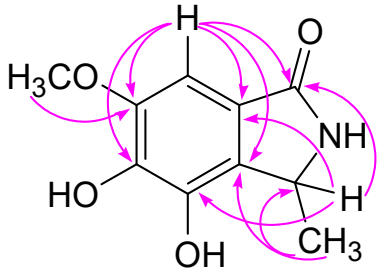

1

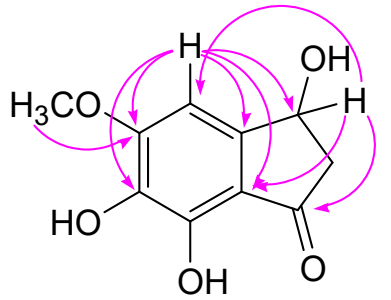

2

Fig.2. Selected HMBC correlations for compounds $\mathbf{1}$ and $\mathbf{2}$. 


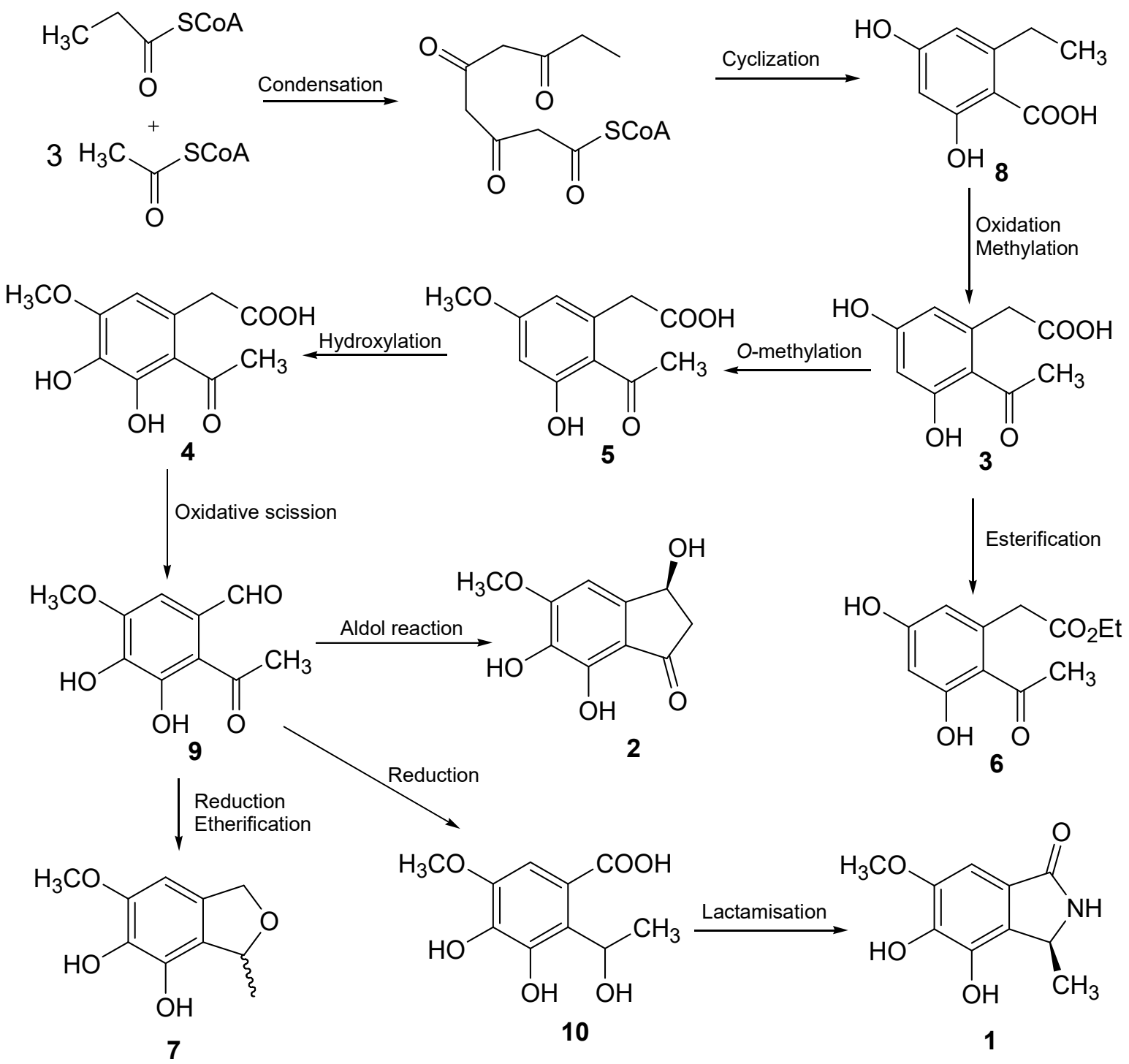

Scheme 1. Proposed biosynthetic origins of polyketides isolated from Chaetosphaeronema achilleae 


\section{Table 1}

${ }^{13} \mathrm{C}$ and ${ }^{1} \mathrm{H}$ NMR spectroscopic data of compounds $\mathbf{1}$ and $\mathbf{2}$ in Methanol $d_{4}$.

\begin{tabular}{lllll}
\hline Position & $\mathbf{1}$ & & $\mathbf{2}$ & \\
& $\delta_{\mathrm{C}}$ & $\delta_{\mathrm{H}}(J$ in Hz) & $\delta_{\mathrm{C}}$ & $\delta_{\mathrm{H}}(J$ in Hz) \\
\hline 1 & 173.6 & $/$ & 205.5 & $/$ \\
2 & $/$ & $/$ & 48.4 & $2.46(\mathrm{brd}, 18.0)$ \\
& & & & $3.02(\mathrm{dd}, 18.0,6.3)$ \\
3 & 52.7 & $4.61(\mathrm{q}, 6.6)$ & 69.1 & $5.22(\mathrm{dd}, 6.3,2.3)$ \\
$3 \mathrm{a}$ & 131.1 & $/$ & 135.1 & \\
4 & 142.0 & $/$ & 101.2 & $6.82(\mathrm{~s})$ \\
5 & 139.7 & $/$ & 157.2 & $/$ \\
6 & 150.6 & $/$ & 144.8 & $/$ \\
7 & 98.4 & $6.89(\mathrm{~s})$ & 149.8 & $/$ \\
$7 \mathrm{a}$ & 123.2 & $/$ & 118.4 & $/$ \\
8 & 19.2 & $1.47(\mathrm{~d}, 6.6)$ & $/$ & $/$ \\
$\mathrm{OCH}_{3}$ & 56.9 & $3.90(\mathrm{~s})$ & 57.0 & $3.97(\mathrm{~s})$ \\
\hline
\end{tabular}

Table 2

MIC values $(\mu \mathrm{g} / \mathrm{mL})$ of the isolated compounds against the tested microorganisms.

\begin{tabular}{lcccccccc}
\hline \multirow{2}{*}{ Organism } & \multicolumn{1}{c}{ MIC $(\mu \mathrm{g} / \mathrm{mL})$} \\
\cline { 2 - 9 } & $\mathbf{1}$ & $\mathbf{2}$ & $\mathbf{3}$ & $\mathbf{4}$ & $\mathbf{5}$ & $\mathbf{6}$ & $\mathbf{7}$ & Reference \\
\hline Candida albicans DSM 1665 & n.i & n.i & n.i & n.i & n.i & n.i & n.i & $33.33 \mathrm{~N}$
\end{tabular}


Micrococcus luteus DSM 1790

Mucor hiemalis DSM 2656

Pichia anomala DSM 6766

Rhodoturula glutinis DSM 10134

Schizosaccharomyces pombe DSM 70572

Bacillus subtilis DSM 10

Chromobacterium violaceum DSM 30191

Escherichia coli DSM 1116

Mycobacterium smegmatis DSM ATCC 700084

Pseudomonas aeruginosa DSM PA14

Staphylococcus aureus DSM 346

$\begin{array}{cccccccc}\text { n.i } & \text { n.i } & \text { n.i } & \text { n.i } & \text { n.i } & \text { n.i } & . n . i & 0.41 \mathrm{O} \\ 66.66 & 33.33 & \text { n.i } & \text { n.i } & \text { n.i } & \text { n.i } & . n . i & 16.66 \mathrm{~N} \\ \text { n.i } & \text { n.i } & \text { n.i } & \text { n.i } & \text { n.i } & \text { n.i } & . n . i & 33.33 \mathrm{~N} \\ \text { n.i } & 66.66 & 66.66 & 66.66 & 66.66 & \text { n.i } & 66.66 & 16.66 \mathrm{~N} \\ \text { n.i } & \text { n.i } & \text { n.i } & \text { n.i } & \text { n.i } & \text { n.i } & 66.66 & 16.66 \mathrm{~N} \\ \text { n.i } & \text { n.i } & \text { n.i } & \text { n.i } & \text { n.i } & \text { n.i } & 33.33 & 4.16 \mathrm{O} \\ \text { n.i } & \text { n.i } & \text { n.i } & \text { n.i } & \text { n.i } & 66.66 & . n . i & 0.41 \mathrm{O} \\ \text { n.i } & \text { n.i } & \text { n.i } & \text { n.i } & \text { n.i } & \text { n.i } & . n . i & 3.33 \mathrm{O} \\ \text { n.i } & \text { n.i } & \text { n.i } & \text { n.i } & \text { n.i } & \text { n.i } & . n . i & 1.66 \mathrm{~K} \\ \text { n.i } & \text { n.i } & \text { n.i } & \text { n.i } & \text { n.i } & \text { n.i } & . n . i & 0.41 \mathrm{G} \\ \text { n.i } & 66.66 & \text { n.i } & 33.33 & \text { n.i } & \text { n.i } & 66.66 & 0.2 \mathrm{O}\end{array}$
n.i: no inhibition, N: Nystatin, O: Oxytetracyclin, K: Kanamycin, G: Gentamycin.

Table 3

Cytotoxicity $\left(\mathrm{IC}_{50}\right)$ against cell lines of some of the isolated compounds.

\begin{tabular}{lcccccccc}
\hline \multicolumn{1}{c}{ Cell line } & \multicolumn{1}{c}{} & \multicolumn{1}{c}{$\mathrm{IC}_{50} \mu \mathrm{g} / \mathrm{mL}$} & \multicolumn{1}{c}{$\mathrm{IC}_{50}(\mathrm{ng} / \mathrm{mL})$} \\
\cline { 2 - 8 } & $\mathbf{1}$ & $\mathbf{2}$ & $\mathbf{3}$ & $\mathbf{4}$ & $\mathbf{5}$ & $\mathbf{6}$ & $\mathbf{7}$ & Epothilon B \\
\hline Mouse fibroblast cell line L929 & 23 & 6.3 & n.a* & 4.3 & n.a & n.a & 5.5 & 0.8 \\
Cervix carcinoma cell line KB-3-1 & 22 & 11 & n.a & 5 & n.a & n.a & 7.5 & 0.06 \\
Human breast adenocarcinoma MCF-7 & n.t** & 1.5 & n.t & n.t & n.t & n.t & n.t & 0.04 \\
Human prostate cancer PC-3 & n.t & n.a & n.t & n.t & n.t & n.t & n.t & 1.1 \\
Squamous carcinoma A431 & n.t & 6.5 & n.t & n.t & n.t & n.t & n.t & 0.1
\end{tabular}




\begin{tabular}{lllllllll} 
Human lung carcinoma A549 & n.t & 16 & n.t & n.t & n.t & n.t & n.t & 2 \\
Ovarian carcinoma SKOV-3 & n.t & 28 & n.t & n.t & n.t & n.t & n.t & 0.12 \\
\hline
\end{tabular}

*n.a: not active, $* *$ n.t: not tested

Table 4

Biofilm inhibition activity of the isolated compounds.

\begin{tabular}{|c|c|c|c|c|c|c|c|}
\hline \multirow[t]{2}{*}{ Conc. $(\mu \mathrm{g} / \mathrm{mL})$} & \multicolumn{6}{|c|}{ Biofilm and Pre-biofilm inhibition $\%$} & \multirow[b]{2}{*}{7} \\
\hline & 1 & 2 & 3 & 4 & 5 & 6 & \\
\hline $\mathrm{MIC}$ & no* & 256 & no & 64.00 & no & no & 64 \\
\hline 256 & 30.56 & 20.78 & 31.00 & 96.82 & 24.28 & 16.64 & 96.18 \\
\hline 128 & 24.96 & 17.15 & 26.16 & 91.95 & 21.68 & $\mathrm{na}^{* *}$ & 15.33 \\
\hline 64 & 24.94 & 15.32 & 25.56 & 23.05 & 20.15 & na & 14.34 \\
\hline 32 & 23.59 & 10.98 & 22.15 & 20.45 & 17.35 & na & 9.32 \\
\hline 16 & 21.19 & 10.12 & 17.28 & 18.01 & 11.16 & na & 8.48 \\
\hline 8 & 19.42 & 9.00 & 11.34 & 11.12 & 9.30 & na & 4.38 \\
\hline 4 & 16.09 & 8.50 & 10.35 & 10.17 & na & na & na \\
\hline
\end{tabular}

*no: not obtained, $* *$ na: not active 
